\title{
COMPETIÇÃO E COOPERAÇÃO NA DINÂMICA GRUPAL
}

ISIDORO MACEDO

Quais os meios de que dispõe o administrador para motivar seus subordinados? Quais suas implicações?

Se, por um lado, o gerente de vendas sabe que muitás vêzes é necessário estimular o espírito de competição entre seus vendedores para obter resultados, por outro, o gerente de produção sabe ser preciso desenvolver o espírito de equipe entre seu pessoal, para que haja o que vender.

Cooperação e competição são conceitos básicos com os quais o administrador tem que se haver constantemente. Em geral, quando num grupo de trabalho existe cooperação satisfatória, não se pensa a respeito dela. É pacificamente aceito, também, que em muitas circunstâncias a competição entre elementos de um grupo é estimulante e produz resultados.

Quando cooperação? Quando competição? Como e por que de uma e de outra?

A finalidade dêste artigo não é chegar a respostas simples e garantidas para qualquer destas perguntas. Ao contrário, é bem possível que sugira mais problemas ao término. Não obstante, espera examinar um aspecto que tem sido extensa-

ISIDORO MACEDO - Professor Adjunto da Escola de Administração de Emprêsas de São Paulo, Departamento de Administração Geral e Relações Industriais. 
mente estudado por especialistas e pesquisadores e que pode fornecer ao administrador elementos úteis para suas decisões. Através de um exame de pesquisas feitas por psicólogos sociais, êste artigo tem o propósito de discutir o fenômeno da cooperação e da competição na dinâmica grupal, em suas implicações para o moral e produtividade na estrutura da organização.

Primeiramente, vamos examinar as pesquisas de DEUTSCH para conceituação dêstes fenômenos no âmbito de pequenos grupos, quanto a aspectos que interessam ao administrador. Há vários estudos que contribuem para a compreensão do fenômeño, como os de PETER BLAU, aqui examinados, que vêm validar e ampliar as observações de DEUTScH, levando-nos à verificação de que o esfôrço competitivo diminui a coesão grupal. Não obstante, BLAU constata que os grupos nos quais prevalece um clima de competição são menos produtivos como grupo, o que não se dá, entretanto, em relação ao indivíduo, que se torna particularmente produtivo devido ao esfôrço de competição.

Assim, a cooperação beneficia a coesão do grupo e isto nos aponta novo caminho à investigação: qual a relação entre coesão grupal e produtividade? Neste sentido, examinamos o trabalho de scHACHTER e seus companheiros sôbre a conceituação do fenômeno da coesão. Este nos leva à consideração de que o moral do grupo é uma função de sua coesão e que "quanto maior a coesão, tanto maior o poder do grupo de influenciar seus membros", o que nos indica, do ponto de vista da administração, que a indução do grupo é de fundamental importância, como é ilustrado pelo comportamento dos grupos "Relay Assembly" e "Bank Wiring", nas observações feitas na Hawthorne.

\section{Definição de Conceitos}

Segundo DANIEL KaTZ (1), "cooperação é o têrmo que descreve um esfôrço conjunto e coordenado de dois ou mais indi-

(1) Daniel Katz, The Concepts of Methods of Social Psychology, in «Fields of Psychology», J. P. Guilford, Van Nestrand, New York, p. 119 . 
víduos". Esta definição é clara e simples, mas para nossos propósitos é preciso ir mais além. MAY e DOOB (2) distinguem êstes conceitos da seguinte maneira: "competição ou cooperação são dirigidas à mesma finalidade social por, pelo menos, dois indivíduos. Na competição, o fim buscado pode ser conseguido em proporções iguais por alguns e não por todos os indivíduos, enquanto que na cooperação, êste fim pòde ser conseguido por todos ou quase todos os indivíduos." MALLER (3) definiu como cooperativa aquela situação que estimula um indivíduo a se esforçar, juntamente com os outros membros de seu grupo, por uma meta que deverá ser partilhada igualmente entre êles. Por outro lado, uma situação competitiva é aquela que estimula o indivíduo a se esforçar, contra outros indivíduos em seu grupo, por uma meta da qual êle espera ser único ou principal possuidor.

Como veremos a seguir, está implícita, na maioria dos conceitos, a noção de que a diferença entre cooperação e competição repousa na diferença da natureza das metas nas duas situações sociais. MORTON DEUTSCH (4) descreve a situação social cooperativa como sendo aquela na qual as metas podem ser conseguidas (até certo ponto) por qualquer indivíduo, sòmente se todos os indivíduos puderem atingir suas respectivas metas. Na situação social competitiva, se a meta é atingida por um dado indivíduo, os demais (até certo ponto) estarão impedidos de atingir suas metas.

Para o propósito de sua teoria, DEUTSCH analisa as situações em suas possibilidades psicológicas quanto a organização, motivação, comunicação, produtividade grupal, orientação, relações interpessoais, comportamento individual e desenvolvimento.

(2) Social Science Research Council Bulletin, «Cooperation and Competition», M. A. May and L. W. Doob, vol. n. 125, 1937 (Cit. in 4).

(3) Teachers' College Contribution to Education, «Cooperation and Competition: An Experimental Study in Motivation», J. B. Maller, n. ${ }^{\circ} 384,1929$ (Cit. in 4).

(4) Human Relations, «A Theory of Cooperation and Competition», Morton Deutsch, vol. II, n. ${ }^{9}$ 2, April 1949, pg. 129. 
Algumas Hipóteses de Deutsch:

O trabalho de DEUTSCH cobre um grande número de hipóteses nestas áreas, das quais salientamos as pertinentes a nossa discussão :

I. Organização. Vários aspectos da organização parecem ser relevantes às diferenças entre cooperação e competição. Estes incluem a interdependência, a homogeneidade de subunidades, a especialização de funções, a estabilidade e a flexibilidade da situação ou organização. É de se esperar, com relação às funções assumidas por indivíduos em cooperação, maior coordenação de esforços, inter-relações mais frequientes - menor homogeneidade com respeito à quantidade de contribuições ou participações - maior especialização de função e maior estabilidade estrutural. Em face de circunstâncias mutáveis, maior flexibilidade organizacional (mudança de funções para adaptar-se a circunstâncias) será manifestada entre indivíduos em cooperação.

II. Motivação (análise de fôrças). A direção das fôrças que operam em indivíduos em cooperação será mais uniforme que a direção das que operam em indivíduos em competição. Será mais em direção ao término de tarefas, isto é, haverá mais pressão no sentido de obter resultado do indivíduo em cooperação. A fôrça do grupo em direção à meta, num grupo cooperativo, será maior que a mesma fôrça num grupo competitivo.

III. Orientação. $\mathrm{O}$ indivíduo em cooperação terá maior conhecimento e respeito dos membros ativos que o indivíduo em competição. Haverá também maior orientação grupal entre os indivíduos em cooperação.

IV. Produtividade do grupo. Os indivíduos em cooperação produzirão mais por unidade de tempo, como um grupo, que os indivíduos em competição (também como um grupo). A produtividade qualitativa dos indivíduos em cooperação (como um grupo) será mais alta e êles aprenderão mais.

V. Relações interpessoais. Os indivíduos em cooperação so rão mais amistosos entre si. A produção do grupo será ava- 
liada mais altamente pelos indivíduos em cooperação. Haverá maior percentagem de funções grupais e individuais entre indivíduos em cooperação e êles terão de si mesmos a percepção de estar produzindo efeitos mais favoráveis em seus companheiros.

VI. Comportamento individual. E de se esperar maior homogeneidade de comportamento nas situações competitivas.

Para verificar suas hipóteses, das quais são parte as mencionadas, DEUTSCH (5) escolheu dez grupos experimentais de cinco alunos de cursos de Introdução à Psicologia. A situação cooperativa foi produzida por instruções que mencionavam, essencialmente, que os esforços do grupo, como um todo, seriam apreciados em comparação aos de quatro outros similarmente constituídos. A nota, ou recompensa que cada membro receberia, seria determinada pelas posições de seu grupo em relação às dos demais.

A situação de competição foi produzida por outro tipo de instruções: cada membro seria apreciado em comparação com os outros quatro membros de seu grupo. Cada um receberia uma nota, de acôrdo com sua própria contribuição.

Com relação aos aspectos do funcionamento do grupo, os resultados indicaram que os indivíduos em cooperação mostraram maior coordenação de esforços, maior diversidade na quantidade de contribuições, pressão para término de tarefa, atenção para com os colegas, comportamento amistoso durante as discussões, avaliação mais favorável do grupo e sua produção, percepção de efeitos favoráveis em seus colegas.

Maior produtividade do grupo ou da organização resultará quando os membros cooperam em suas inter-relações. A intercomunicação de idéias, a coordenação de esforços, o comportamento amistoso e o orgulho de seu próprio grupo, que são básicos à harmonia grupal e à eficiência, parecem ser desmem-

(5) Ibid., «An Experimental Study of the Effects of Cooperation and Competition upon Group Process», Morton Deutsch, vol. II, July 1949, pg. 199. 
brados quando os elementos se percebem competindo por metas mùtuamente exclusivas. Além disso, há indicações de que competitividade produz maior insegurança pessoal (expectativa de hostilidade em outros indivíduos) do que a cooperação.

\section{Outros Estudos}

O estudo de cooperação e competição numa burocracia, por PETER BLAU (6), compara dois grupos de entrevistadores numa agência de serviço público, nos Estados Unidos. Revela que os grupos que mais competem são menos produtivos, enquanto que os indivíduos que mais competem nos grupos competitivos são relativamente mais produtivos. A ansiedade sôbre a produção e as práticas de competição consequientes interferem com a eficiência do desempenho no primeiro grupo. Em contraste, as condições no segundo grupo dão margem ao aparecimento de normas de cooperação que eliminam tendências competitivas e favorecem o comportamento amistoso nas relações interpessoais. A maior coesão, através da redução de ansiedade, faz êste grupo mais produtivo que o primeiro. Na ausência de coesão social, o esfôrço competitivo para desempenho que seja notado é um caminho alternativo para diminuir a ansiedade sôbre "status". Isto explica, na conclusão de BLAU, o paradoxo de que competição e produtividade são inversamente relacionadas para grupos, mas diretamente relacionadas para os indivíduos nos grupos em competição.

Esta observação de BLAU (7) corrobora as conclusões de LIKERT e KATZ (8) de que o grupo mais preocupado com pro-

(6) American Journal of Sociology, "Cooperation and Competition in a Bureaucracy», Peter M. Blau, vol. 59, n. ${ }^{\circ} 6$, May 1954, pg. 530/5.

(7) Peter M. Blau, The Dynamics of Bureaucracy, The University of Chicago Press, Chicago, 1955, pg. 49.

(8) Rensis Likert e Daniel Katz, Supervisory Practices and Organizational Structures as They Affect Employee Productivity and Morale, in «Human Factors in Management», S. D. Hoslett, Harper pg. 89. 
dutividade era menos produtivo que o grupo não preocupado com êste fator. A ansiedade sôbre a produtividade induzia os entrevistadores a concentrarem-se cegamente em suas metas, a expensas de outras considerações. A prevalência do comportamento competitivo enfraquecia a coesão social e isto, por sua vez, reduzia a eficiência. A coesão social realçava a eficiência operacional, primeiramente facilitando a cooperação e em segundo lugar reduzindo a ansiedade quanto a "status".

A ansiedade com relação à produção destruia a equanimidade de que o funcionário necessitava para o bom desempenho de seu trabalho. Mesmo no grupo coeso a produtividade foi baixa quando um novo supervisor criou ansiedade aguda e difundida. De outra forma, contudo, êste grupo era mais produtivo, porque a coesão social reduzia a ansiedade por tornar a posição do indivíduo, dentro do grupo, independente de sua produtividade. o esfôrço competitivo para se destacar oferecia uma alternativa de aliviar esta ansiedade, mas uma alternativa que minava a coesão grupal. A hipótese de que a coesão do grupo tinha o mesmo efeito de diminuir a ansiedade quanto a "status", explica o paradoxo de que o grupo que competia menos e o individuo que competia mais, no grupo em competição, eram particularmente produtivos.

Em suas experimentações, GotTHEIL (9) sugere que os indivíduos se tornam mais dispostos a aceitar o grupo e percebê-lo mais favoràvelmente, após haver desempenhado uma tarefa cooperativa. Isto não foi o caso nem no grupo de contrôle nem nos grupos em competição. Os grupos cooperativos não sòmente revelaram maior disposição para aceitar os indivíduos com quem cooperavam, mas demonstraram, de um modo geral, uma disposição melhor. Isto sugere que o esfôrço cooperativo do grupo (socialização) não origina, necessàriamente, frustração e agressão. Ao contrário, faz com que o indivíduo se mostre com melhor disposição quanto a suas. percepçōes sociais.

(9) Sociometry, *Changes in Social Perceptions Contingent on Competing or Cooperating», Edward Gottheil, vol. 18, n. 2, May 1955, pg. $132 / 7$. 
Da mesma forma que BLAU e DEUTSCH $(4,7)$, whitTMore (10) chegou à conclusão de que os indivíduos menos capazes quanto à velocidade têm mais a lucrar na competição, mas todos os indivíduos executam mais pobremente suas tarefas quando em competição.

\section{Coesão e Produtividade}

Vimos que cooperação é benéfica para a coesão grupal e seria interessante examinarmos agora os efeitos, tanto da cooperação, quanto da coesão, com relação à produtividade e ao moral.

SCHACHTER e seus companheiros (11) acham que o conceito de coesão representa uma tentativa de formalizar ou simplesmente pôr em palavras os fenômenos básicos da continuidade grupal, o "cimento" que une os membros do grupo e mantém suas relações uns com os outros. As discussões com relação a esta propriedade grupal têm sido pouco estruturadas e a coesão tem sido definida de várias maneiras, tais como referindo-se a moral, a ficar juntos, a produtividade, a poder, a envolvimento na tarefa, a sentimentos de pertencer ao grupo, a partilha na compreensão das funções e no bom trabalho de equipe.

Ainda de acôrdo com schachter, é possível, a grosso modo, classificar estas várias definições em dois grupos: um que gravita principalmente em tôrno de aspectos particulares do comportamento ou processo grupal, em que a palavra coesão se refere a moral, eficiência, "ésprit de corps". A atração do grupo para seus membros pode estar implícita em tais formulações, mas é usualmente secundária. $\mathrm{O}$ outro grupo de definições diz respeito exclusivamente à atração dos membros

(10) Journal of Abnormal and Social Psychology, «The Influence of Competition on Performance: An Experimental Study», Irving C. Whittmore, vol. XIX, pg. 236.

(11) Human Relations, «An Experimental Study of Cohesiveness and Productivity», Stanley Schachter et. al., vol. IV, n. ${ }^{\circ}$ 3, Aug. 1951, pg. 229 . 
do grupo. Coesão, pois, é a resultante média das fôrças agindo sôbre os membros, na direção do grupo. Não se preocupa com premissas a respeito do comportamento ou da "atmosfera" de grupos coesos.

A distinção entre estas duas fórmulas torna-se clara em seus tratamentos das relações da coesão com a produtividade do grupo. A formulação do binômio coesão-moral sugere que, desde que o grupo coeso é distinguido pelo bom moral e, desde que um grupo coeso gosta de outro nas mesmas condições, dando-se bem, deve seguir que quanto mais coesos os grupos, mais produtivos devem ser.

\section{A Indução Grupal}

A teoria da coesão-atração de SCHACHTER leva a "quanto maior a coesão, tanto maior o poder do grupo de influenciar seus membros." (11) $O$ autor prossegue para dizer que, se concebermos a produtividade de um grupo em parte como uma função do sucesso do grupo de influenciar seus membros, torna-se claro que a coesão deveria ser uma das determinantes da produtividade. Se a coesão vem aumentar ou diminuir a produtividade, isso é largamente determinado pela direção da indução grupal. Ao procurar diminuir a produção, os grupos de coesão baixa devem ser mais produtivos que os de alto índice de coesão. Em ambos os casos, os grupos mais coesos obtêm mais êxito no influenciar seus membros.

Grupos de alto índice de coesão devem (dentro de limites especificos) ser mais bem sucedidos em vencer fôrças com direção oposta à direção induzida pelo grupo. BREKowITZ (12) acha que mesmo quando não mais se aplica pressão direta, os membros dos grupos de maior coesão tendem a comportar-se dentro de maior conformidade aos padrões percebidos do grupo. Quando os padrões são para maior produção, um grupo de alta coesão tenderá a aumentar a produção. Isto implica em uma aceitação não meramente temporária de in-

(12) Human Relations, «Group Standards, Cohesiveness and Productivity», Leonard Brekowitz, vol. 7, n. 4, 1954, pg. 509. 
fluência, mas numa aceitação mais permanente da atitude percebida.

\section{Moral e Produtividade}

Desde que a cooperação leva a maior coesão do grupo $(4,5$, $7,11,12)$, podemos dizer que pode ser benéfica para se conseguir produtividade. Entretanto, é necessário ressaltar que o fator crucial é a direção da indução grupal. Isto pode ser ilustrado pelo comportamento do grupo de "Montagem de Relês", na experiência da HAWTHORNE (13), onde a situação experimental criou uma situação de maior cooperação entre as moças, resultando em maior produtividade e moral mais elevado. Não obstante, a coesão do grupo "Bank Wiring", da mesma experiência, resultou em prejuízo à produtividade, mas não quanto ao moral.

Este mesmo problema é estudado no trabalho de KAHN e KATZ (14) que concluem ter o critério duplo de produtividade e moral muitas determinantes comuns. Isto nos sugere que o efeito do comportamento de supervisores sôbre a motivação pode ser básico para a compreensão de diferenças de produtividade. Contudo, a coexistência de elevado moral e produtividade, ou mais frequientemente, baixo moral e alta produtividade, é suficientemente comum. Uma explicação desta discrepância talvez seja que o supervisor pode aumentar a produtividade de duas maneiras razoàvelmente independentes entre si : ou através de suas habilidades técnicas, ou através de sua habilidade de motivar seus subordinados. Outra explicação importante é que a produtividade pode ser aumentada em alguns cásos pelas práticas da companhia, inclusive por sanções negativas que afetam adversamente o moral.

Estes autores prosseguem para dizer que é possível que a falta de correlação entre moral e produtividade, nestes estudos, re-

(13) F. J. Roethlisberger e W. J. Dickson, Management and the Worker, Harvard University Press, 1939.

(14) R. L. Kahn e D. Katz, Leadership Practices in Relation to Productivity and Morale, in «Group Dynamics», Catwright e Zander, Row, Petersen \& Co., Evanston, Ill., 1953, pg. 612. 
flita o fato de estar-se tratando sòmente com medidas de custos gerais de produção, isto é, quantidades numa unidade de tempo. Se incluisse os custos de rotação de pessoal e as ausências e perdas por rejeição, a correlação entre moral e produtividade poderia ser mais alta.

Um outro ponto que pode ser trazido aqui é o de que quando indivíduos cooperam, são mais amistosos, avaliam mais altamente os resultados do grupo, há maior percentagem de funções grupais e percebem-se como tendo efeito mais favorável em seus colegas $(4,5,15)$. Um produto da interação social é o desenvolvimento de normas que refletem uma estrutura de referência determinada pelo grupo no perceber uma situação. Tais normas sociais aparecem com a formação de um grupo, como é ilustrado nos novos e mais altos padrões de produção estabelecidos com o aparecimento da "organização social informal" na sala de experiência de "Montagem de Relês", na Hawthorne. Uma vez estabelecidas tais normas, a conduta do grupo pode persistir por muito tempo, conforme ilustra a restrição de produção do grupo da "Bank Wiring" (15).

\section{Sumário}

Pelo que já vimos, temos que cooperação, sujeitando os membros do grupo a uma situação de menor tensão, os leva à harmonia e à coesão $(4,5,15)$.

Nossa preocupação é a de tentar determinar o efeito da cooperação sôbre a produtividade e a moral dentro da estrutura da organização. Somos lembrados por woRTHy (16) que "determinar o nível do moral é útil, principalmente como um modo de diagnosticar problemas organizacionais - não é um fim em si mesmo". Isto põe em evidência a sensação de que o âmago da questão é produtividade, ainda mais que há indicações (14) de ser baixa a correlação entre produtividade e

(15) Morris S. Viteles, Motivation and Morale in Industry, W. W. Norton \& Co., Inc., New York, 1953.

(16) James C. Worthy, Factors Influencing Employee Morale, in «Human Factors in Management», S. D. Hoslett, Harper, pg. 302. 
moral. Seja como fôr, as conclusões parecem apontar para o fato de que situações de cooperação resultam em comportamento amistoso, coesão, moral elevado e, incidentalmente, maior produtividade. Para esta última, é necessário que a indução grupal seja na direção de padrões mais elevados de produção. (11)

Podemos finalizar dizendo que a cooperação, dentro do grupo, é um elemento que a administração pode utilizar para aumentar a produtividade das tarefas grupais, através da indução do grupo na direção e no sentido dos objetivos administrativos de padrões de maior produção, conseguindo uma aceitação mais permanente e não meramente temporária da influência administrativa. 